\title{
Comparison of Cellular Sensitivity to a Split Radiation Dose and a Combination of a Single Radiation Dose and Electromagnetic Field Exposure
}

\author{
Angela Chinhengo, Antonio Serafin, \& John Akudugu* \\ Division of Radiobiology, Department of Medical Imaging and Clinical Oncology, Faculty of \\ Medicine and Health Sciences, Stellenbosch University, South Africa \\ *Address all correspondence to: John Akudugu, Division of Radiobiology, Department of Medical Imaging and \\ Clinical Oncology, Faculty of Medicine and Health Sciences, Stellenbosch University, Tygerberg 7505, South Africa; \\ Tel.: +27-21-938-9942, E-mail: jakudugu@sun.ac.za
}

\begin{abstract}
HIV-positive individuals, who are at high risk of developing cancers such as Kaposi's sarcoma, tend to be more sensitive to ionizing radiation and are at a higher risk of developing severe side effects during radiotherapy. To enhance therapeutic benefit in this patient cohort, new and noninvasive methods are needed to sensitize cancer cells and reduce therapeutic doses. To partially address this need, the effects of 100 and $1000 \mathrm{~Hz}$ electromagnetic fields (EMF) on the radiosensitivity of Chinese hamster lung fibroblasts (V79) and human melanoma cells (MeWo) were evaluated, using the colony forming assay. The surviving fraction (SF) of V79 cells exposed to a $1000 \mathrm{~Hz}$ field for $30 \mathrm{~min}$, followed by $2 \mathrm{~Gy}$ of X-rays $6 \mathrm{~h}$ later $(\mathrm{SF}=0.6833 \pm 0.0067)$, was significantly higher than that obtained when cells were irradiated twice with $1.5 \mathrm{~Gy}$ X-rays, $6 \mathrm{~h}$ apart $(\mathrm{SF}=0.5620 \pm 0.0026 ; P=0.0008)$. On the other hand, the combination of EMF exposure and irradiation was more toxic $(\mathrm{SF}=0.3350 \pm 0.0050)$ in the melanoma cells than the split radiation treatment $(\mathrm{SF}=0.3825 \pm 0.0035 ; P=0.0008)$. These data suggest that use of EMF may significantly reduce the total radiation dose during radiotherapy and minimize normal tissue toxicity without compromising tumor control.
\end{abstract}

KEY WORDS: electromagnetic fields, HIV-positive cancer patients, radiomodulatory effects

\section{INTRODUCTION}

The treatment of HIV/AIDS-related Kaposi's sarcoma (KS) (also known as epidemic $\mathrm{KS}$ ), as for any other cancer, is largely influenced by factors such as disease site and extent, symptoms, and overall patient condition. Epidemic KS may be treated with several modalities. The first step in the treatment of epidemic KS should be optimal control of the HIV infection, using highly active antiretroviral therapy (HAART), which is known to reduce the severity of KS in AIDS patients. ${ }^{1}$ HAART alone, however, may not reverse progression of KS, and other treatments are necessary, such as surgery, chemotherapy, radiation therapy, and biological therapy. The best response is found with radiation therapy. However, HIV/AIDS patients may not fully recover from the side effects of radiation therapy because a compromised immune system may not have the capacity to repair radiation-induced damage. ${ }^{2}$ This cohort of cancer patients tends to show higher normal tissue toxicity during conventional radiotherapy than their HIV-negative counterparts. ${ }^{3-7}$ 
Radiation therapy can also further weaken the immune system, and so patients with HIV/AIDS may not be able to complete the full course of treatment without risking severe side effects, such as life-threatening infections. Therefore, alternative treatment modalities are needed for the treatment of epidemic KS.

Some investigators suggest a single dose of $8 \mathrm{~Gy} \mathrm{X}$-rays as optimal for all cases of cutaneous KS, with less normal tissue toxicity than the conventional regimens. ${ }^{2,4}$ However, such a high dose may cause greater tissue toxicity, from which HIV/AIDS patients may not recover. Conventional fractionated radiation therapy (given as $20 \mathrm{~Gy}$ in 10 fractions or 40 Gy in 20 fractions) has also been used to treat KS in HIV/AIDS patients, and it was noted that acute toxicity increased with increasing radiation dose. ${ }^{4}$ Because the number of HIV/AIDS patients presenting with KS is increasing and patients are expected to exhibit lower levels of treatment tolerance compared to their non-AIDS infected counterparts, combining radiation therapy with other modalities might be beneficial for epidemic Kaposi's sarcoma patients.

Electromagnetic fields have been shown to inhibit disease progression and prolong patient survival, with minimal or no side effects. ${ }^{8-10}$ In vitro studies have also shown that extremely low frequency magnetic fields can affect cell death processes like apoptosis. ${ }^{11-15}$ Significant evidence points toward the potential of electromagnetic fields for future use in noninvasive and nontoxic therapeutic approaches for cancer treatment. ${ }^{16}$ Results from a recent cell culture-based study revealed that electromagnetic fields can act either as radiosensitizers or radioprotectors, depending on field frequency and cell type. ${ }^{17}$ This outcome suggests that informed combination of low to medium frequency electromagnetic fields and radiotherapy might be very useful in managing cancers, especially those in HIV-positive patients. Most entities that interact synergistically with EMFs are mutagens; therefore synergism between EMFs and ionizing radiation should be considered more seriously.

Using murine fibroblasts and human melanoma cells, this study compares the efficacy of a larger dose of X-rays, given in two fractions, with that of a lower dose given in combination with low to medium frequency electromagnetic fields.

\section{MATERIALS AND METHODS}

\section{A. Cell Cultures}

The V79 cell line (ATCC ${ }^{\circledR}$ Number: CCL-93 ${ }^{\mathrm{TM}}$ ), used to mimic normal tissue, was derived from Chinese hamster lung and was obtained from Flow Laboratories (Irvine, Scotland). The human melanoma cell line, MeWo (ATCC ${ }^{\circledR}$ Number: HTB-65 ${ }^{\mathrm{TM}}$ ) was a gift from F. Zölzer and C. Streffer (University of Essen, Germany). The cells were routinely grown as monolayers in $75-\mathrm{cm}^{2}$ flasks in Minimum Essential Medium (MEM) supplemented with $20 \%$ fetal bovine serum ( $10 \%$ for V79 cells), penicillin $(100 \mathrm{U} / \mathrm{mL})$, streptomycin $(100 \mu \mathrm{g} / \mathrm{mL})$ and incubated at $37^{\circ} \mathrm{C}$ in a humidified atmosphere $(95 \%$ air, $5 \% \mathrm{CO}_{2}$ ), and were used for experiments at $80-90 \%$ confluence. For experiments, cell cultures were trypsinized and 200 to 500 cells seeded per $25-\mathrm{cm}^{2}$ tissue culture flask in 
$10 \mathrm{~mL}$ of medium, and left to settle for $2 \mathrm{~h}$ (V79) or $4 \mathrm{~h}$ (MeWo). The cells were subsequently irradiated with split doses of X-rays $6 \mathrm{~h}$ apart, or exposed to an electromagnetic field $6 \mathrm{~h}$ prior to or following an X-ray irradiation.

\section{B. Inadiation of Cell Cultures}

Cells were irradiated at room temperature $\left(20^{\circ} \mathrm{C}\right)$ at a dose rate of $1 \mathrm{~Gy} / \mathrm{min}$ to either a single dose of 3 Gy or 1.5 Gy followed by 1.5 Gy 6 h later, using a Faxitron MultiRad 160 X-ray irradiator (Faxitron Bioptics, Tucson, AZ, USA). A 6-h interval was chosen because it is the optimum time between fractions in the clinical setting when two fractions are administered per day in a radiotherapy regimen. Sham-irradiated (0 Gy) cultures were left on the turntable of the Faxitron X-ray irradiator for 2 min with the $\mathrm{X}$-ray source turned off. Cell cultures used for assessing the radiomodulatory effects of electromagnetic fields were irradiated with a single dose of $2 \mathrm{~Gy}$.

\section{Electromagnetic Field Exposure}

Electromagnetic field generation and exposure were performed as previously described. ${ }^{17}$ Briefly, an EMEM oscillator amplifier was used to produce $27.125 \mathrm{MHz}$ fields that square-wave amplitude-modulated at 100 or $1000 \mathrm{~Hz}$, with a peak-to-peak amplitude of 5 V (EMEM Devices Rife Machine, Model \#1-2012B, Boulder, CO, USA). The modulating frequencies were generated using a GME frequency generator with an output impedance of $50 \Omega$ and a duty cycle of 50\% (GME Technology, Model \#: SG-10, Pomona, CA, USA). The resulting radiofrequency (RF) was then broadcast via a double bubble argon plasma ray tube, which was assumed to function as an antenna transmitting at approximately $27.12 \mathrm{MHz}$. The estimated magnetic flux densities, peak electric fields, and current densities in the cell cultures ranged from 0.30 to $1.44 \mu \mathrm{T}$, 0.09 to $0.42 \mathrm{~V} / \mathrm{m}$, and 0.14 to $0.63 \mathrm{~A} / \mathrm{m}^{2}$, respectively. ${ }^{17}$ Cell cultures were exposed to the broadcast radiofrequency for $30 \mathrm{~min}, 6 \mathrm{~h}$ before or after X-ray irradiation. For sham EMF exposure $(0 \mathrm{~Hz})$, the control samples were treated as described with the plasma ray tube turned off.

\section{Clonogenic Cell Survival}

Cell survival was evaluated by the colony forming assay as described previously. ${ }^{17}$ Briefly, irradiated and EMF-exposed cell cultures were incubated for 7 days (V79) and 14 days (MeWo) to form colonies. The colonies were then fixed in glacial acetic acid/ methanol/water $(1: 1: 8, \mathrm{v} / \mathrm{v} / \mathrm{v})$, stained with $0.01 \%$ amido black in fixative, air-dried, counted, and surviving fractions calculated. ${ }^{17}$

To assess the effect of EMF exposure on radiosensitivity, the ratio of the surviving fraction of each combination treatment to that of the split irradiation regimen (relative response, RR) was determined. The criteria for increased radioresistance, no effect, and enhancement of radiosensitivity by EMF are $R R>1.0, R R=1.0$, and $R R<1.0$, respectively.

Volume 9, Issue 1, 2019 


\section{E. Statistical Analysis}

Statistical analyses were performed using the GraphPad Prism (GraphPad Software, San Diego, CA, USA) computer program. To compare two data sets, the unpaired two-sided $t$-test was used. A $P$-value of less than 0.05 indicates a statistically significant difference between the data sets. Data were presented as the mean ( \pm SEM) from at least three in-

dependent experiments. For each experiment, three replicates were assessed. Errors for calculated quantities were derived, using appropriate error propagation formulae.

\section{RESULTS AND DISC USSION}

This study sought to compare the outcomes of a split dose of radiation and an acute dose given with electromagnetic fields, using Chinese hamster lung fibroblasts (V79) and human melanoma cells (MeWo). When the V79 and MeWo cells were irradiated with $\mathrm{X}$-rays to an acute dose of $3 \mathrm{~Gy}$, the surviving fractions emerged as $0.4753 \pm 0.0253$ and $0.2401 \pm 0.0099$, respectively (Figs. 1 and 2). The disparity in intrinsic radiosensitivity in these cell lines cannot be attributed to differences in the status of the p53 gene, as the gene is mutated in both cell lines. ${ }^{18,19}$ Radiation-induced cell death is not necessarily dependent on p53 status. ${ }^{20}$ The higher radiosensitivity of MeWo cells relative to V79 cells is, therefore, likely due to activation of other genes upstream of p53 (e.g., ATM) that are responsible for $\mathrm{p} 53$-independent cell death in the former cell line ${ }^{21}$ making the cells more radiosensitive. Also, differences in radiation-induced DNA repair capacity cannot explain the disparity in radiosensitivity. The role of DNA repair in cellular radiosensitivity was interrogated by giving the 3-Gy dose as two fractions of $1.5 \mathrm{~Gy}, 6 \mathrm{~h}$ apart. The recovery from the radiation insult from the first fraction resulted in a 1.18-fold increase in the surviving fraction to $0.5620 \pm 0.0026$ for the fibroblasts (see Fig. 1, Table 1), and a 1.59-fold increase to $0.3825 \pm 0.0035$ for the melanoma cells (see Fig. 2 and Table 1). This means that the melanoma cells are about 3-fold more efficient in DNA repair than the fibroblasts. The finding that the malignant melanoma cells (MeWo) recover to a larger extent than the apparently normal Chinese hamster lung fibroblasts (V79) seems to suggest that conventional fractionated radiation therapy alone might not be very beneficial for patients presenting with lesions such as epidemic KS.

However, to test whether fractionated radiotherapy is superior to combining a single dose of radiation with EMF exposure, surviving fractions at 3 Gy given in two fractions, $6 \mathrm{~h}$ apart, were compared with those obtained when cells were treated with a combination of 2 Gy of X-rays and an EMF of $100 \mathrm{~Hz}$ or $1000 \mathrm{~Hz}$. The data presented in Fig. 2 show significantly higher and similar levels of survival when the V79 cells were treated with a combination of 2 Gy and EMF exposure $(100$ or $1000 \mathrm{~Hz})$ than when cells were irradiated with $3 \mathrm{~Gy}$, given in two fractions, $6 \mathrm{~h}$ apart $(P \leq 0.0132)$. This phenomenon is independent of the sequence of X-ray irradiation and EMF exposure. The corresponding relative responses (RR) ranged from 1.11 to 1.32 , indicating a percentage increase in radioresistance of $11 \%$ to $32 \%$, respectively (see Table 1 ). No EMF-related cytotoxicity was apparent in the fibroblasts, with a surviving fraction of 


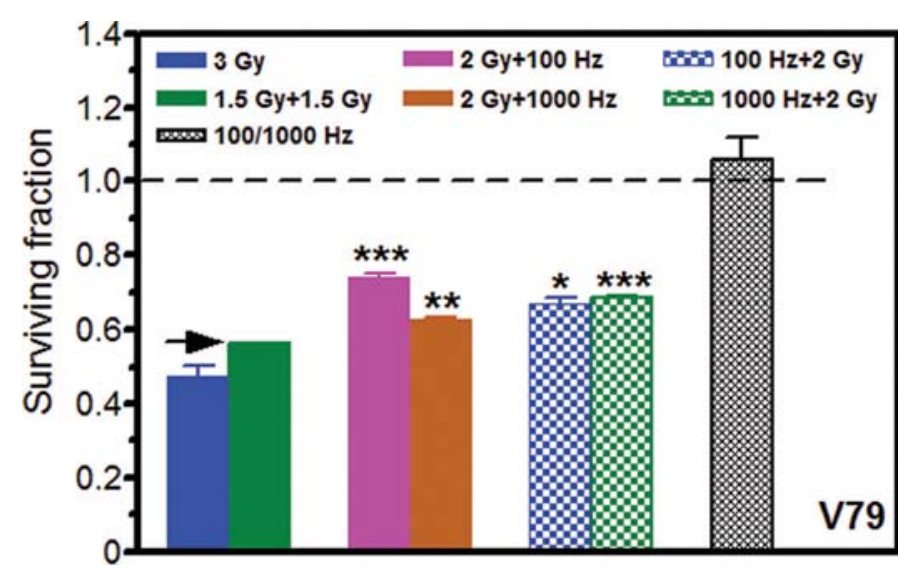

FIG. 1: Mean surviving fractions $( \pm$ SEM) from three independent experiments for Chinese hamster lung fibroblasts (V79) following various treatment protocols. Split doses of X-rays (1.5 Gy per fraction) or combinations of 2 Gy and EMF exposure were given $6 \mathrm{~h}$ apart. The horizontal dashed line represents the surviving fraction of untreated cultures. The solid arrow indicates the split dose surviving fraction against which combination treatments are compared. $* * * P \leq$ $0.0009 ; * * 0.0009 \leq P \leq 0.001 ; * 0.01 \leq P \leq 0.04$.

$1.06 \pm 0.03$ (see Fig. 1). Put together, these findings suggest that if the Chinese hamster lung fibroblasts are truly representative of normal tissue, combining radiotherapy with EMF exposure could be beneficial. Such combined modality therapy may permit up to $30 \%$ reduction in total radiation dose and a minimization of normal tissue toxicity.

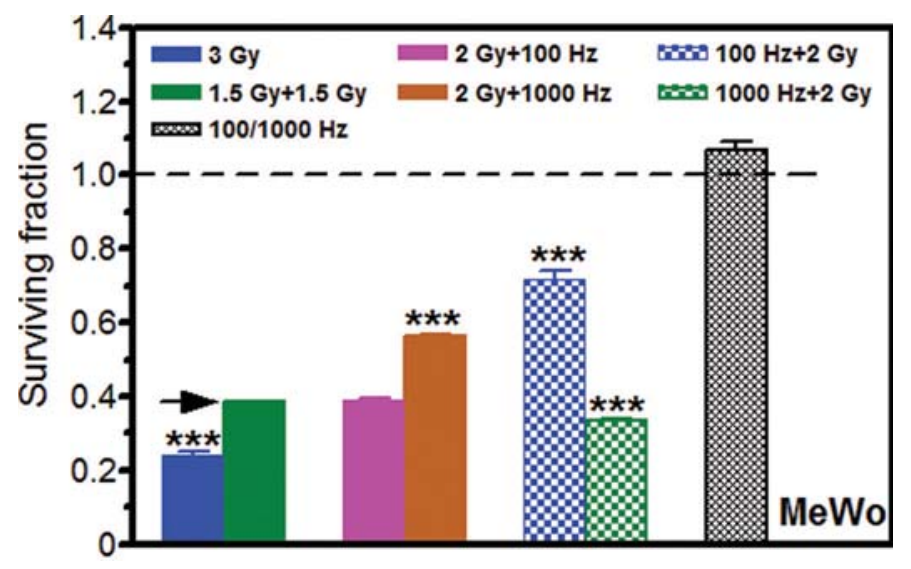

FIG. 2: Mean surviving fractions ( \pm SEM) from three independent experiments for human melanoma cells (MeWo) following various treatment protocols. Split doses of X-rays (1.5 Gy per fraction) or combinations of $2 \mathrm{~Gy}$ and EMF exposure were given $6 \mathrm{~h}$ apart. The horizontal dashed line represents the surviving fraction of untreated cultures. The solid arrow indicates the split dose surviving fraction against which combination treatments are compared. $* * * P \leq 0.0009$.

Volume 9, Issue 1, 2019 
TABLE 1: Summary of radiosensitivity for Chinese hamster lung fibroblasts (V79) and human melanoma cells (MeWo), following X-ray irradiation (3 Gy, 1.5 Gy + 1.5 Gy, or $2 \mathrm{~Gy}$ ). The two fractions of the split irradiation were given $6 \mathrm{~h}$ apart, and EMF exposure $(100 \mathrm{or} 1000 \mathrm{~Hz})$ was given $6 \mathrm{~h}$ before or after X-ray irradiation. SF and RR denote surviving fraction and relative radiosensitivity with respect to the split irradiation regimen, respectively.

\begin{tabular}{|c|c|c|c|}
\hline Cell line & Treatment & $\mathbf{S F}^{*}$ & $\mathbf{R R}^{\#}$ \\
\hline \multirow{3}{*}{ V79 } & $3 \mathrm{~Gy}$ & $0.4753 \pm 0.0253$ & - \\
& $1.5 \mathrm{~Gy}+1.5 \mathrm{~Gy}$ & $0.5620 \pm 0.0026$ & 1.00 \\
\hline \multirow{7}{*}{ MeWo } & $2 \mathrm{~Gy}+100 \mathrm{~Hz}$ & $0.7400 \pm 0.0108$ & $1.32 \pm 0.01$ \\
\cline { 2 - 4 } & $2 \mathrm{~Gy}+1000 \mathrm{~Hz}$ & $0.6250 \pm 0.0065$ & $1.11 \pm 0.01$ \\
\cline { 2 - 4 } & $100 \mathrm{~Hz}+2 \mathrm{~Gy}$ & $0.6675 \pm 0.0165$ & $1.19 \pm 0.02$ \\
\cline { 2 - 4 } & $1000 \mathrm{~Hz}+2 \mathrm{~Gy}$ & $0.6833 \pm 0.0067$ & $1.22 \pm 0.01$ \\
\hline \multirow{3}{*}{} & $3 \mathrm{~Gy}$ & $0.2401 \pm 0.0099$ & - \\
\cline { 2 - 4 } & $1.5 \mathrm{~Gy}+1.5 \mathrm{~Gy}$ & $0.3825 \pm 0.0035$ & 1.00 \\
\cline { 2 - 4 } & $2 \mathrm{~Gy}+100 \mathrm{~Hz}$ & $0.3900 \pm 0.0058$ & $1.02 \pm 0.01$ \\
\cline { 2 - 4 } & $2 \mathrm{~Gy}+1000 \mathrm{~Hz}$ & $0.5625 \pm 0.0075$ & $1.88 \pm 0.04$ \\
\cline { 2 - 4 } & $100 \mathrm{~Hz}+2 \mathrm{~Gy}$ & $0.7175 \pm 0.0236$ & $0.88 \pm 0.01$ \\
\hline
\end{tabular}

$*$ Mean \pm SEM

\#Mean \pm error: errors were calculated using appropriate error propagation formulae

The enhanced radioresistance in the fibroblasts might also benefit wound management, especially in the setting of preoperative radiotherapy where difficulties in wound healing are frequently encountered. ${ }^{22-27}$ However, if the increased radioresistance of the fibroblasts is linked to an accelerated proliferation, the intended promotion of wound healing may not be realized, because such proliferation is known to correlate with wound healing morbidity. ${ }^{28}$

A 2-Gy irradiation of the melanoma cells followed by EMF exposure (at 100 or $1000 \mathrm{~Hz}$ ) $6 \mathrm{~h}$ later yielded either the same or an increase in radioresistance, in comparison with that found for the split dose irradiation (see Fig. 2). The corresponding relative responses emerged as $1.02 \pm 0.01$ and $1.47 \pm 0.01$ (see Table 1). Also, when these cells were pre-exposed to a $100 \mathrm{~Hz}$ electromagnetic field, an even higher surviving fraction was obtained $(\mathrm{RR}=1.88 \pm 0.04$; a more than $80 \%$ increase in cell survival). These data indicate that pre-irradiation followed by $100 \mathrm{~Hz}$ exposure, or pre-exposure to $100 \mathrm{~Hz}$ followed by irradiation may lead to tumor resistance to radiotherapy. However, pre-exposure of the malignant cells to $1000 \mathrm{~Hz}$ resulted in a modest but significant reduction in cell survival $(P=0.0008)$. The corresponding relative response was $0.88 \pm 0.01$, representing a $12 \%$ decrease in cell survival. As in the case of the V79 cells, exposure of the MeWo cells to both EMF frequencies was nontoxic (see Fig. 2). 


\section{CONCLUSION}

Put together, the findings of this study suggest that a 30 min exposure to a $1000 \mathrm{~Hz}$ EMF followed $6 \mathrm{~h}$ later by 2 Gy of X-rays may be beneficial to HIV/AIDS patients with epidemic KS, because this treatment radiosensitizes tumors and enhances the radioresistance of fibroblasts. This will likely improve tumor control and reduce normal tissue toxicity. EMFs, therefore, could be used with radiotherapy to reduce the total radiation absorbed dose administered to patients. This can have a significant positive impact on the management of patients with superficial tumors, especially those who are immunocompromised. There is a great need for the standardization of EMF therapy so that it may be used in cancer treatment. It is noninvasive and may potentially replace or enhance other therapeutic modalities, such as radiation therapy, surgery, and chemotherapy. As the number of HIV/AIDS cases continues to rise, epidemic KS cases are also on the increase. Radiation therapy plays a palliative role, and combining it with EMF therapy may even lead to better treatment outcomes. The data reported here demonstrate that the use of EMF in combination with radiation therapy may yield better results than conventional or hypofractionated radiation therapy.

\section{ACKNOWEDGMENIS}

This work is based on research supported in part by the National Research Foundation of South Africa (Grant Numbers: 85703, 92741, 100157). Funding from the Faculty of Medicine and Health Sciences (Stellenbosch University) and the Cancer Association of South Africa is also acknowledged.

\section{REFERENCES}

1. Cattelan AM, Calabrò ML, De Rossi A, Aversa SML, Barbierato M, Trevenzoli M, Gasperini P, Zanchetta M, Cadrobbi P, Monfardini S, Chieco-Bianchi L. Long-term clinical outcome of AIDSrelated Kaposi's sarcoma during highly active antiretroviral therapy. Int J Oncol. 2005;27:779-85.

2. Berson AM, Quivey JM, Harris JW, Wara WM. Radiation therapy for AIDS related Kaposi's sarcoma. Int J Radiat Oncol Biol Phys. 1990;19:569-75.

3. Watkins EB, Findlay P, Gelmann E, Lane HC, Zabell A. Enhanced mucosal reactions in AIDS patients receiving oropharyngeal irradiation. Int J Radiat Oncol Biol Phys. 1987;13:1403-8.

4. Stelzer JK, Griffin TW. A randomized prospective trial of radiation therapy for AIDS-associated Kaposi's sarcoma. Int J Radiat Oncol Biol Phys. 1993;27:1057-61.

5. Mourad WF, Hu KS, Ishihara D, Shourbaji RA, Lin W, Kumar M, Jacobson AS, Tran T, Manolidis S, Urken M, Persky M, Harrison L. Tolerance and toxicity of primary radiation therapy in the management of seropositive HIV patients with squamous cell carcinoma of the head and neck. Laryngoscope. 2013;123:1178-83.

6. Herd O, Francies F, Slabbert J, Baeyens A. The effect of HIV and antiretroviral therapy on chromosomal radiosensitivity. J AIDS Clin Res. 2014;5:397.

7. Ulrike K, Markus H, Thomas H, Ellen H, Barbara S, Rainer F, Distel LV. NNRTI-based antiretroviral therapy may increase risk of radiation induced side effects in HIV-1-infected patients. Radiother Oncol. 2015;116:323-30.

Volume 9, Issue 1, 2019 
8. Kirson ED, Dbaly V, Tovaryš F, Vymazal J, Soustiel JF, Itzhaki A, Mordechovich D, SteinbergShapira S, Gurvich Z, Schneiderman R, Wasserman Y, Salzberg M, Ryffel B, Goldsher D, Dekel E, Palti Y. Alternating electric fields arrest cell proliferation in animal tumor models and human brain tumors. Proc Natl Acad Sci U S A. 2007;104:10152-7.

9. Barbault A, Costa FP, Bottger B, Munden RF, Bomholt F, Kuster N, Pasche B. Amplitude-modulated electromagnetic fields for the treatment of cancer: discovery of tumor-specific frequencies and assessment of a novel therapeutic approach. J Exp Clin Cancer Res. 2009;28:51.

10. Verginadis I, Velalopoulou A, Karagounis I, Simos I, Peschos D, Karkabounas S, Evangelou A. Beneficial effects of electromagnetic radiation in cancer. In: Bashir SO, editor. Electromagnetic radiation. Shanghai: InTech; 2012. p. 249-68.

11. Simkó M, Kriehuber R, Weiss DG, Luben RA. Effects of $50 \mathrm{~Hz}$ EMF exposure on micronucleus formation and apoptosis in transformed and nontransformed human cell lines. Bioelectromagnetics. 1998;19:85-91.

12. Tofani S. Electromagnetic energy as a bridge between atomic and cellular levels in the genetics approach to cancer treatment. Curr Top Med Chem. 2015;15:572-8.

13. Tofani S, Barone D, Cintarino M, de Santi MM, Ferrara A, Orlassino R, Ossola P, Peroglio F, Rolfo $\mathrm{K}$, Ronchetto F. Static and ELF magnetic fields induce tumor growth inhibition and apoptosis. Bioelectromagnetics. 2001;22:419-28.

14. Sarimov R, Markova E, Johansson F, Jenssen D, Belyaev I. Exposure to ELF magnetic field tuned to $\mathrm{Zn}$ inhibits growth of cancer cells. Bioelectromagnetics. 2005;26:631-8.

15. Crocetti S, Beyer C, Schade G, Egli M, Fröhlich J, Franco-Obregón A. Low intensity and frequency pulsed electromagnetic fields selectively impair breast cancer cell viability. PLoS One. 2013;8(9):e72944.

16. Vadalà M, Morales-Medina JC, Vallelunga A, Palmieri B, Laurino C, Iannitti T. Mechanisms and therapeutic effectiveness of pulsed electromagnetic field therapy in oncology. Cancer Med. 2016;5:3128-39.

17. Chinhengo A, Serafin A, Hamman B, Akudugu J. Electromagnetic fields induce frequency-dependent radioprotection and radiosensitization in in vitro cell cultures. Plasma Med. 2018;8:163-75.

18. Albino AP, Vidal MJ, McNutt NS, Shea CR, Prieto VG, Nanus DM, Palmer JM, Hayward NK. Mutation and expression of the p53 gene in human malignant melanoma. Melanoma Res. 1994;4:35-45.

19. Chaung W, Mi L-J, Boorstein RJ. The p53 status of Chinese hamster V79 cells frequently used for studies on DNA damage and DNA repair. Nucleic Acids Res. 1997;25:992-4.

20. Clarke AR, Purdie CA, Harrison DJ, Morris RG, Bird CC, Hooper ML, Wyllie AH. Thymocyte apoptosis induced by p53-dependent and independent pathways. Nature. 1993;362:849-52.

21. Zhivotovsky B, Kroemer G. Apoptosis and genomic instability. Nat Rev Mol Cell Biol. 2004;5:752-62.

22. Bujko K, Suit HD, Springfield DS, Convery K. Wound healing after preoperative radiation for sarcoma of soft tissue. Surg Gynecol Obstet. 1993;176:124-34.

23. Gu Q, Wang D, Cui C, Gao Y, Xia G, Cui X. Effects of radiation on wound healing. J Environ Pathol Toxicol Oncol. 1998;17:117-23.

24. Kunisada T, Ngan SY, Powell G, Choong PFM. Wound complications following pre-operative radiotherapy for soft tissue sarcoma. Eur J Surg Oncol. 2002;28:75-9.

25. Mendelsohn FA, Divino CM, Reis ED, Kerstein MD. Wound care after radiation therapy. Adv Skin Wound Care. 2002;15:216-24.

26. Haubner F, Ohmann E, Pohl F, Strutz J, Gassner HG. Wound healing after radiation therapy: review of the literature. Radiat Oncol. 2012;7:162.

27. Griffin AM, Dickie CI, Catton CN, Chung PWM, Ferguson PC, Wunder JS, O'Sullivan B. The influence of time interval between preoperative radiation and surgical resection on the development of wound healing complications in extremity soft tissue sarcoma. Ann Surg Oncol. 2015;22:2824-30.

28. Akudugu JM, Bell RS, Catton C, Davis AM, O’Sullivan B, Waldron J, Wunder JS, Hill RP. Clonogenic survival and cytokinesis-blocked binucleation of skin fibroblasts and normal tissue complications in soft tissue sarcoma patients treated with preoperative radiotherapy. Radiother Oncol. 2004;72:103-12. 